\title{
Sustainability Aspects of Barrier-Free Information and Communication Technology (ICT) in the Private Sector
}

\author{
Daryoush Daniel Vaziri \\ University of applied science Bonn-Rhein-Sieg, D-53757 Sankt Augustin, Germany \\ Tel.: +49 (0) 2241865123 \\ Daryoush.Vaziri@h-brs.de
}

\begin{abstract}
This paper will examine sustainability aspects of accessible information and communication technology for the private sector. First, the introduction highlights the current barriers against and drivers for barrier-free ICT. Second, the ICT scope for the further examination will be declared. Common accepted usability design clusters will be used to illustrate accessibility design principles. Regarding the impact of barrier-free ICT on sustainability aspects, three dimensions will be determined. For each dimension several positive effects, initiated by the implementation of accessible ICT, will be demonstrated.
\end{abstract}

Keywords: Accessibility, ICT, Accessible ICT, barrier-free ICT, Sustainability, Barrier-free design, Accessible Design.

\section{Introduction}

With the latest information and communication technology (ICT), disabled people are able to undertake a variety of tasks that would otherwise be difficult or impossible. They have the opportunity to participate in everyday life as well as in daily business. However, this new quality of life is significantly dependent on enterprise decisions made at the beginning of specific IT-projects. According to paragraph 11 of the equality act for disabled people in Germany, carriers of public governance are compelled to design barrier-free information technology (Department of justice 2007). Similar efforts can be found in the legislative texts of e. g. the United Kingdom (Directgov 2010) or the United States (Department of justice 2009). Even though the abovementioned paragraphs indicate, that the governments will work towards, to prevail on commercial enterprises to design accessible IT, the current involvement seems nominal.

A study, executed by Bloor research in the year 2009, examined the current and planned accessibility status of organizations' ICT Systems. Referring to the 141 completed surveys, significant increases cannot be expected. Barriers to improve accessibility, mentioned by the participants, are illustrated in figure 1 (Abrahams 2009).

The poor support and commitment of the senior management results in an insufficient budget available for improving accessibility, which is in fact the reason for the major lack of understanding / training and the inadequate condition of development and testing tools. 


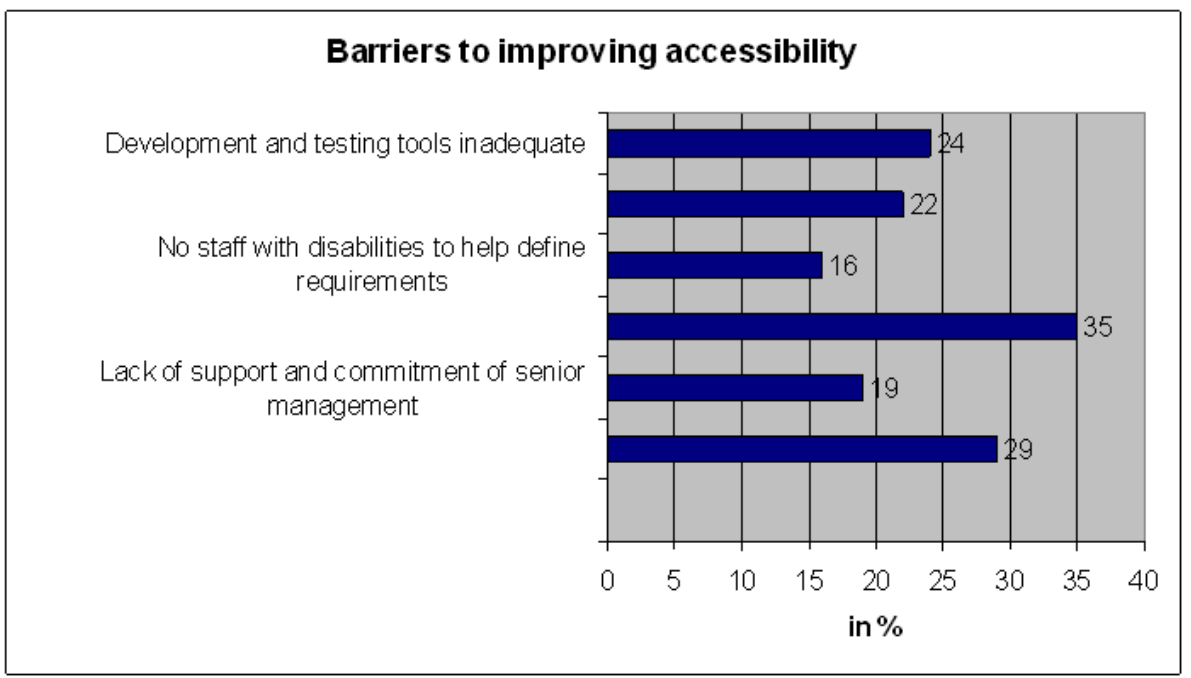

Fig. 1. Barriers to improving accessibility ${ }^{1}$

In contrast, the aforementioned study also revealed important drivers to improve accessibility, demonstrated in figure $2^{2}$ (Abrahams 2009).

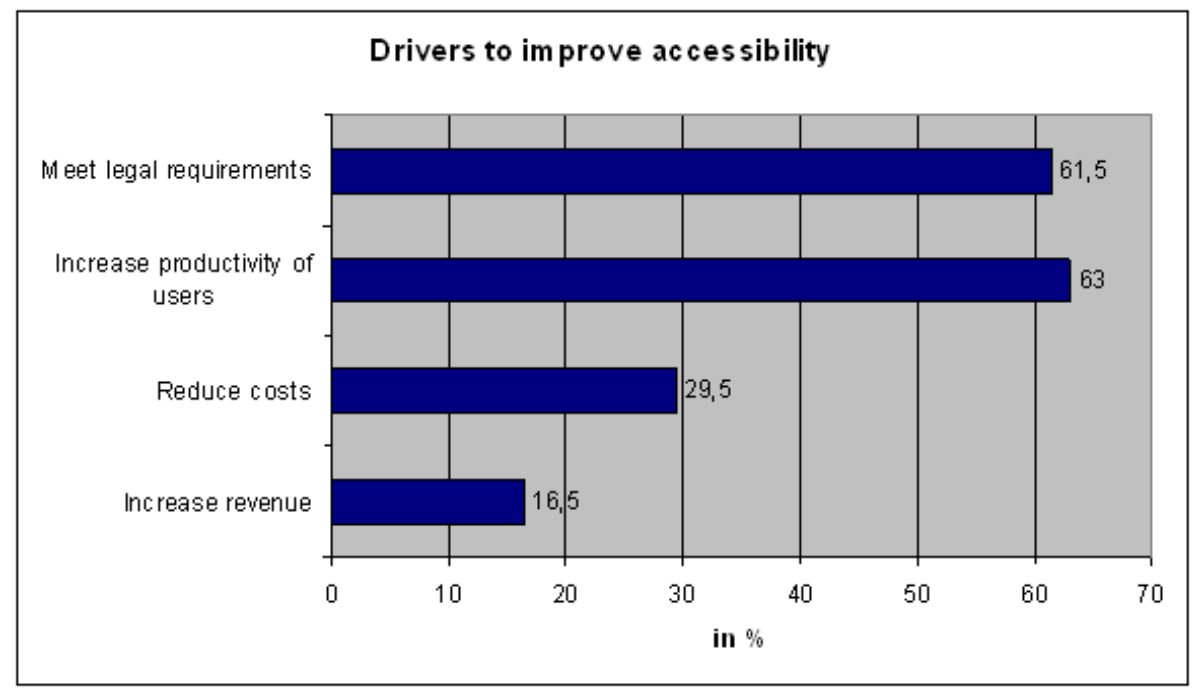

Fig. 2. Drivers to improve accessibility ${ }^{3}$

\footnotetext{
${ }^{1}$ Self provided figure.

${ }^{2}$ Data is based on an averaging of the original study.

${ }^{3}$ Self provided figure.
} 
The minor importance of accessibility as a driver for cost -cutting and sales increases seems to be a decisive reason for the poor support and commitment of the management level. Legal requirements and user productivity as the most frequently mentioned drivers for accessibility do not seem to have a major impact on management decisions (Abrahams 2009).

This emphasizes the need to sensitize the management for the holistic advantageousness of an accessible IT-Infrastructure from an economic, ecological and social point of view.

\section{ICT Scope for Barrier -Free Design and Development}

Within this paper the sustainability of barrier-free business application software will be examined. Therefore business application software can be defined as a package of essential tools to increase efficiency and effectiveness of business processes by supporting employees or customers and enabling parallelization, digitalization and automation of business transactions (Verma 2009). Furthermore the examination will focus on enterprise websites as a communication channel to the customer and thus as an essential platform for generating revenues. Within this article the presentation and process logic of business applications and enterprise websites are of special importance.

\section{Design Principles for Barrier -Free ICT}

There are many types of disabilities which have a bearing on the development of accessible ICT. Some of them are listed below (Galitz 2002):

- Visual disabilities

- Hearing disabilities

- Physical movement disabilities

- Speech or language disabilities

- Cognitive disabilities

- Seizure disorders

To regard all of these disabilities, several design principles have been compiled and published.

As we mainly examine the sustainability of barrier-free ICT, the design principles will only be explained briefly. Therefore the principles are aggregated into established clusters of usability depicted in figure 3. This classification can be derived from various resources, concerning with usability engineering (W3C 2008; Agarwal et al. 2010; Lidwell et al. 2010; Lányi et al. 2007).

\section{Perceptibility}

Perceptibility implies that content presented on a website or within an application is perceivable for every user regardless of his disability (Pühretmair, Miesenberger 2005). To fulfil this criterion, developers can integrate additional functionalities like scalability or the two-channel principle. The latter is used to provide multiple 


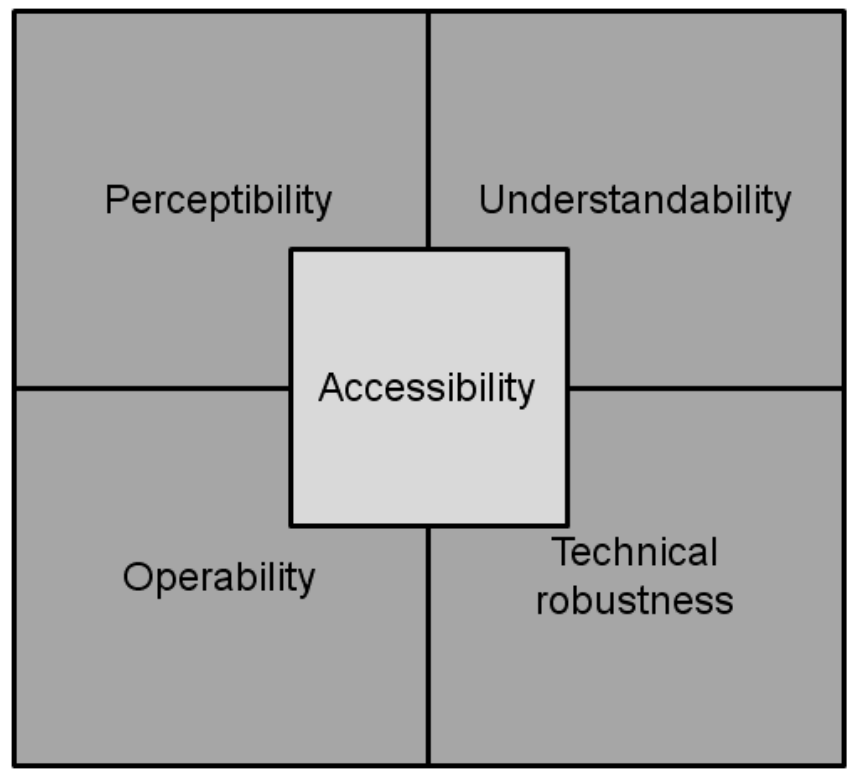

Fig. 3. Clusters for accessibility design principles ${ }^{4}$

opportunities for the user to succeed a specific task (Wegge, Zimmermann 2007). Furthermore the content can be enriched by alternative tags, which replenishes nontextual content with descriptions. Another crucial, often underestimated, criterion is the colour contrast of content. Users with visual disabilities for example might have a dyschromatopsia and therefore would not be able to differentiate between red and green content. Imagine a top manager, afflicted with dyschromatopsia, reviewing operating numbers that are represented in a usual traffic light-system.

\section{Understandability}

This criterion intends to make text content readable and understandable as well as to make the application processes appear and operate predictable. Therefore developers can for example programmatically determine the default language of the application or label unusual words and abbreviations. A Screen-Reader, used by many disabled people to read the content presented on a website or within an application, can only help the user when text or text parts are labelled correctly.

To render application processes predictable to the user it is an advantage to highlight any focused components. Furthermore navigational mechanisms that are repeated on multiple web pages or application screens should be consistent if possible. Components that share the same functionality should use a same identifier like a symbol or name (W3C 2008).

\footnotetext{
${ }^{4}$ Self provided figure.
} 


\section{Operability}

To make applications operable for disabled people all functionality should be triggerable through a keyboard. Some people afflicted by physical movement disabilities are not able to use a computer mouse. The only way for them to navigate through the content of a web site or application is to use the tabulator-key of the keyboard. Focus order and focus visibility are important and have to be considered. Hence, developers should avoid keyboard traps, which would kill the operability at a stroke. Generally the user should be provided with enough time to use, read and process the content. Seizure disorders also have to be taken into account when developing a website or application. So, rapidly flashing content should be avoided [0].

\section{Technical robustness and technical openness}

Website or application content must be robust enough, so that a variety of assistive technologies can interpret the content reliably. Compatibility of current and future technologies has to be ensured. In addition, fulfilling this principle prohibits redundant data and multiple versions. Special features of robust content are listed below (W3C 2008):

- Elements have complete start and end tags

- Elements are nested according to their specifications

- Elements do not contain duplicate attributes

- Any ID's are unique (specific exceptions allowed)

For detailed information on accessible designing principles the author references the interested reader to the resources, mentioned above.

There are some more aspects, which might come into consideration, when designing accessible ICT, e.g. maintainability, efficiency, memorability, learnability. The author decided only to describe the most frequently mentioned principles found in literature (W3C 2008; Agarwal et al. 2010; Lidwell et al. 2010; Lányi et al. 2007), as this paper mainly focuses on sustainability aspects of barrier-free ICT. Nevertheless, these additional aspects can have impact on sustainability as well and therefore should not be disregarded when designing accessible ICT.

\section{Sustainability Aspects of Barrier -Free ICT}

Information and communication technology is one of the most significant promoters to sustainability in everyday life as well as in daily business. Due to ICT many transactions, even whole processes, can be accomplished automatically or/and with minimal effort. Besides economy that experienced a robust growth, environment and society can be declared as beneficiaries as well (World economic forum 2009). Therefore the following examination of the sustainability of accessible ICT will be illustrated from a business economic, ecological and social point of view. These sustainability dimensions are derived from several sources, which cover a wide topic area (Nga, Soo 2010; Madruga 2002; European commission 2001; Lehtonen 2004). Hence, 
the author applies these dimensions to append this topic to a familiar classification of sustainability dimensions.

None of the following paragraphs can be regarded isolated. Instead they feature intermeshed fields, which can profit by implementing accessible ICT.

\subsection{Business Economic Aspects}

If we imply the purpose of running a business is to earn profit by supplying the demand of customers with products or services that are generated with optimal allocated resources, under the consideration of competitors' activities and stakeholders' interests, then we can abstract a specific scope of data to measure the success of that business ${ }^{5}$ :

- Market share

- Image / Reputation

- Costs

- Revenues

The following examples will demonstrate how barrier-free ICT can positively impact the abovementioned fields. Figure 4 provides a graphical overview of this section.

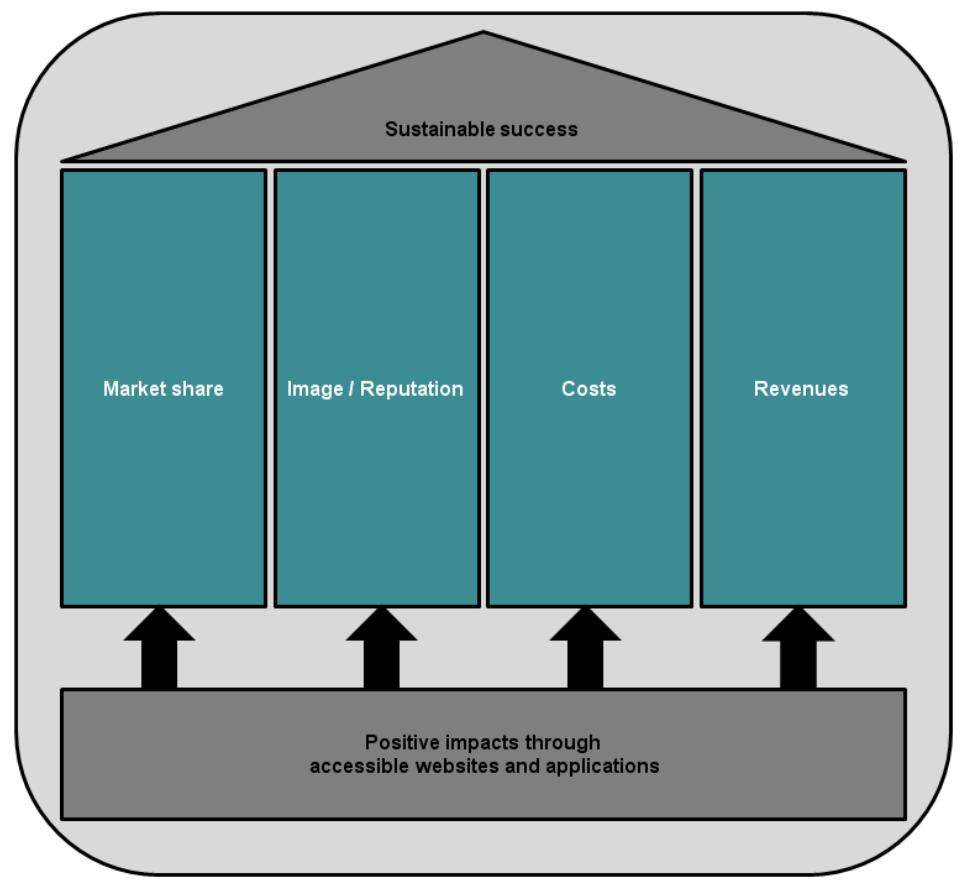

Fig. 4. Positive impacts of accessible ICT components ${ }^{6}$

\footnotetext{
${ }^{5}$ No claim to completeness.

${ }^{6}$ Self provided figure.
} 


\section{Market share}

The process of globalization significantly amplifies the national and international competition for enterprises. As the supplement rises, customers find a variety of alternative products at lower prices. However, globalization also results in a rise of demand. Through ICT, products can be sold to any customer at any time around the globe. Increasing market share becomes essential for enterprises to persist in such a competitive landscape (Rüttimann 2007).

If we define an enterprise website as a firm's representation on the Internet with the opportunity to diffuse information, to acquire new customers and to offer and sell products and services this would definitely be one efficient way to increase market share.

Therefore the website must be available and accessible to as many Internet users as possible. Worldwide there are about 650 million people with disabilities (United Nations enable 2007). Europe numerated approximately 500 Mio inhabitants in the year 2009 (Marcu 2009). 67.1 percent out of those 500 Mio inhabitants were declared as working-age population (Eurostat 2010). 15.7 percent, respectively 52.7 Mio people of that working population either have a long-standing health problem or a disability (Eurostat 2003). Every fourth European declares, having a member of their family affected by a disability (The European research Group's 2001). Those people usually are not able to use common inaccessible websites easily and thus approximately more than a fifth of the spending power in Europe is not used efficiently. Figure 5 provides a graphical presentation of the proportion between working-age population and people with long-standing health problems or disabilities within that working-age population.

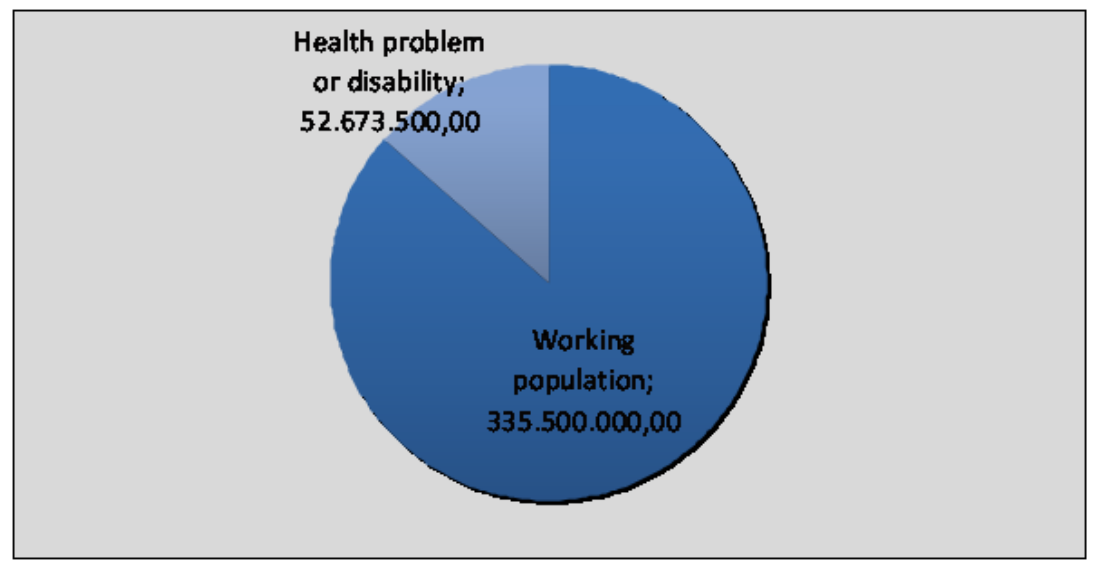

Fig. 5. Proportion between working-age population and health problems/disabilities

All this data and the aforementioned fact, that many enterprises in the private sector still are quite reserved in terms of investing in accessible ICT, leads into one logic consequence: 
To increase market share and to benefit from idle revenue potential, investing in barrier-free ICT is a serious option.

Accessible ICT supports the realization of certain success factors crucial to a growth in market share.

- Findability

Accessibility offers some inherent benefits for search engine optimization. Google, MSN or Yahoo for example use specific rules called algorithms to find and rank web sites. These algorithms could be the most frequent disabled user on a website. They show some important behaviour, similar to these of certain disabled people. Search Engine algorithms are blind, navigate with JavaScript disabled and stop cold if a link is not operable. One of the principles of accessibility is to ensure, that a blind user, who is unable to use Javascript, can navigate and understand the website. Therefore, fulfilling this accessibility principle increases the findability of a website and thus can increase market share (Thatcher et al. 2006).

- Customer Satisfaction

As nowadays "Time is Money", customers always seek for the fastest, easiest and most convenient way to fulfil their tasks on the internet. Accessible websites or applications provide a properly written source code. Therefore the content structure is optimized and enriched by specific tag words, which help the user to find and understand content more comfortable (Clark 2002). As the development of accessible websites / applications considers and evaluates criteria like, the font size, colour contrasts, text colours and more, the perceptibility for the customer is improved. Furthermore, the customer is able to adapt the website or application to its requirements. By optimizing content structures, the loading time reduces as well and thereby helps the customer to complete activities faster (Thatcher et al. 2006). In addition accessible websites / applications provide more fault-tolerant search engines. Hence, the user is able to fulfil specific tasks more efficiently, e.g. searching the content (IBM 2009). Finally, barrier-free websites / applications offer a high grade of technical robustness respectively technical openness. This means the customer is able to operate within the system by different devices or web browsers. All of these features refer to a software ergonomic nature. A customer satisfaction survey examined the importance of customer requirements for QFD-software ${ }^{7}$. The results of this survey are illustrated in figure 6 (Herzwurm et al.1997). Software ergonomics were stated as one of the most important software requirements for customers. Besides, accessible ICT affects additional software requirements, mentioned in figure 6 , e. g. visualization, individual adaptability, interpretation or data exchange with other programs.

Summarizing, accessible ICT can have a major impact on customer satisfaction.

- Conversion rate

As the website can generate more satisfied users, some of them might remember the website and return to it. Over time the conversion rate could increase and the customer base could be expanded.

${ }^{7}$ Quality function deployment software. 


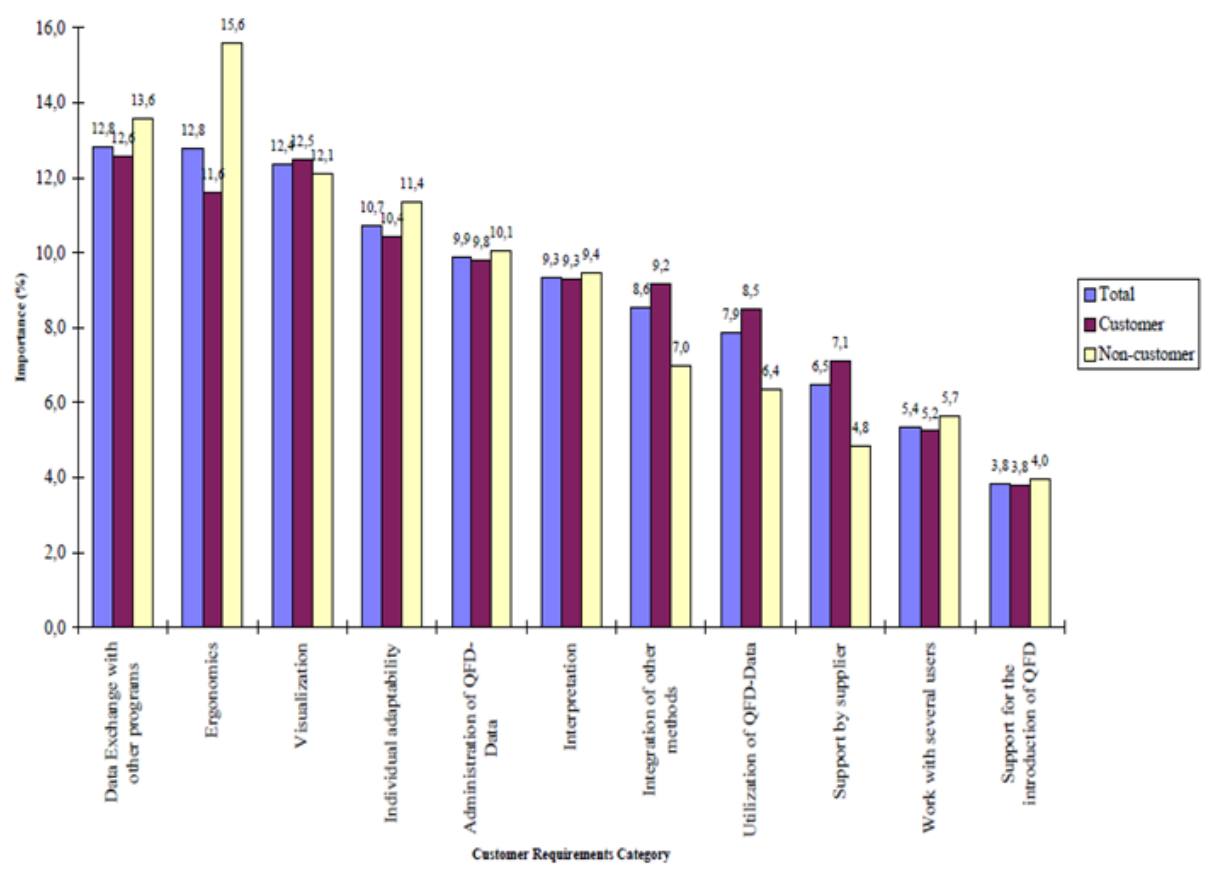

Fig. 6. Customer requirements for QFD-software (Herzwurm et al. 1997)

- Device independence

As mentioned in chapter 3, accessible websites / applications provide a higher grade of technical robustness and openness. So, the access to the website / application is available for more browsers and devices, e.g. Safari Browser and Apple iphone. Therefore more customers with various technologies are able to use the website / application efficiently (Thatcher et al. 2006).

\section{Image / Reputation}

Providing accessible ICT will affect in a positive image and a growth in reputation, as the enterprise attends to the interests and needs of disabled people and thus considers inherent social desires of people without disabilities (OneVoice 2010). From a strategic point of view, accessible ICT provides to fulfil Corporate Social Strategy (CSR) objectives, which are essential to improve an enterprises' image and reputation within the society (De Andrés et al. 2009).

\section{Costs}

Investing in accessible ICT often results in improved technical performance. Many organizations can realize direct cost savings by improving their technical performance through barrier-free ICT (Thatcher et al. 2006). Some of the cost savings are listed below (Thatcher et al. 2006). 
- Personnel costs

Efforts for maintenance are reduced when implementing accessible ICT, as redundant data and multiple versions of the website / application are avoided. As mentioned in Chapter 3, a major goal of the principle "technical robustness / technical openness" is to prohibit these flaws.

- Server capacity

Accessibility reduces server loading and thus saves on additional server costs by decreasing the need of server capacity. The optimized content structure provides more efficient server workloads.

- Management of multiple versions

The need for creating multiple versions for different devices decreases by implementing accessible ICT, as the technical robustness and openness, mentioned in chapter 3, is a key principle. This relates to the aforementioned paragraph "personnel costs" as maintenance activities decrease with only one operating version.

- Cost of upgrading

The cost of upgrading to new technologies decreases, as accessibility takes advantage of advanced technologies and is prepared for future technologies. This is also included in the principle "Technical robustness and openness", listed in chapter 3.

The cost criterion also contains additional aspects, mentioned in chapter 3, like maintainability or efficiency. These aspects can greatly benefit by investing in accessible ICT and might have a major affect on ICT costs.

\section{Revenues}

The revenue potential can increase by the improvement of abovementioned fields. Increasing market share and reputation will expand the customer base and raise revenues, while simultaneously will ensure a major constant liquidity. Cutting direct costs through accessible ICT enables the enterprise to optimize allocation of financial resources and to transfer them to promising business units.

\subsection{Ecological Aspects}

Citizens of developed countries, in their role as consumers, are becoming increasingly aware of problems associated with the deterioration of the environment due to the functionality of the market. As a result they exhibit preferences for green products and processes, revealed in an increased willingness to pay for them (García-Gallego, Georgantzís 2011). "The code of conduct" on data centres energy efficiency, published by the European institute for energy, reveals the environmental problems of increasing energy consumption. According to that article, it is extremely recommended to optimize power distribution, cooling infrastructure, IT equipment and IT output to increase energy efficiency and thereby to minimize energy consumption (Institute for energy 2008). 
Accessible ICT reduces traffic and server capacities, by providing an optimized data and process structure. Thus energy consumption will deplete (Djokic 2010). Additionally, accessible ICT decreases location bound operations for everyone. This can result in a lower use of technologies causing $\mathrm{CO} 2$ emissions. Implementing barrierfree ICT is one step to transport a firms' ecological awareness to the consumer.

\subsection{Social Aspects}

Accessible ICT provides many social aspects, especially for people with disabilities. To participate in everyday life as well as in daily business is a crucial key factor for disabled people to be equally acknowledged within the society. But not only disabled people can benefit from accessible ICT. Therefore some hypotheses will be constructed in the following paragraphs:

- Workforce potential increases

Enterprises that offer an accessible working environment will be able to choose their employees from a major pool. Expertise of older, experienced people as well as disabled "hidden potentials" can be acquired and deployed as valuable manpower. Accessible ICT makes the work more comfortable and reduces illnesses / injuries related to a software ergonomic nature. Older and disabled people do both benefit from this. Especially the principles "perceptibility" and "operability" provide the appropriate criteria, which will be stated in the paragraph "labour conditions increase".

- Adaptation to demographic transition

By 2050, the proportion of the world's population aged over 65 will be twice as high as currently. Estimations illustrate an increase from $7.6 \%$ currently to $16.2 \%$. This would make about 1 billion people aged over 65 (Standard \& Poors 2010). In contrast, the portion of people ages 16-24 is decreasing. Referring to a study, executed by "USA Today", this age segment declined, from $66 \%$ in the year 2000, to 55\% in the year 2010 (Cauchon 2010). This persistent tendency leads to a decreasing working-age population (Population reference bureau 2010). Enterprises have to face a dwindling workforce potential, while the quantity of older personnel is ascending. This circumstance requires specific adaptations of future business applications to fit the requirements of elderly employees and to prevent negative health effects from the entire staff, induced by software usage. As mentioned in section 4.1 accessible ICT improves software ergonomics and thereby provides more comfortable working environments for elderly people as well as for disabled people.

- Labour conditions increase

Improvements in labour conditions can be acquired for people with and without disabilities. As we mentioned issues related to a software ergonomic nature before, some examples for improving labour conditions, respectively software ergonomics will be stated below:

- Adjustments of font size

- High contrasts 
- Reduced loading times

- Different colour schemes

- Voice recognition and command

- Touchscreen operation

- Assistant / help functionalities

- Error avoidance functionalities

Many more aspects of accessible websites / applications would improve labour conditions.

- Gap between people with and without disabilities

According to a study concerning the American territory, executed by the Kessler foundation, only $21 \%$ of disabled people are employed. In comparison, $59 \%$ of people without disabilities have an employment. In terms of internet access, only $54 \%$ of people with disabilities can use the World Wide Web, while $85 \%$ of people without disabilities are able to use this platform (Kessler, Catts 2010). Accessible ICT will help to close this gap and will ensure equal conditions for disabled people.

\section{Conclusion}

This article demonstrated the reluctance of enterprises when deciding about accessible ICT. Drivers for and barriers against accessible ICT were identified. Application software and enterprise websites were declared as the ICT Scope for the investigation. Design principles for barrier-free ICT, sorted into usability clusters, illustrated opportunities to develop accessible ICT. Three dimensions of sustainability were defined and the positive impact of accessible ICT on these dimensions was examined.

The current literature mainly covers the accessibility of web sites, so the author applied these sources. Nevertheless, the accessibility of applications can be derived from these sources as well, as web applications are considered by the latest accessibility requirements.

The inquiry showed that investing in accessibility can be worthwhile and wider might be essential for enterprises to survive in the near future.

\section{References}

Abrahams, P.: Survey of attitudes to accessible ICT. Bloor Research, 2-9 (July 2009)

Agarwal, B.B., Tayal, S.P., Gupta, M.: Software engineering and testing: An introduction, p. 105. Jones and Bartlett Publishers, Massachusetts (2010)

Cauchon, D.: American workforce growing grayer, published in: USA today (2010), http: / /www. usatoday.com/money/workplace/2010-12-14-olderworkers-employment_N.htm?csp=usat.me

Clark, J.: Building accessible websites, p. 96 et seq. New Riders publishing, Indiana (2002)

De Andrés, J., Lorca, P., Martínez, A.B.: Economic and Financial Factors for the Adoption and Visibility Effects of Web Accessibility:The Case of European Banks. Journal of the American society for Information science and technology 60(9), 1769-1770 (2009) 
Department of Justice (Germany). Equality Act for disabled people. Paragraph 11 (December 2007)

Department of Justice (USA). Americans with Disabilities Act (January 1, 2009),

http: / / www . ada.gov/pubs / adastatute08.htm

Directgov. Disabled peoples's rights in everyday life (2010), http: / / www.direct.gov.uk/en/DisabledPeople/ RightsAndobligations/DG_4019061

Djokic, D.: Web Accessibility in the European Union, 11th Libre Software Meeting, Bordeaux, p. 18 et seq. (2010),

http: // bearstech.com/media/Web\%20Accessibility 20 in $\% 20$ the\% $20 \mathrm{EU} \% 20-\% 20 \mathrm{FINAL}$. pdf

European commission, Agriculture directorate general. A Framework for indicators for the economic and social dimensions of sustainable agriculture and rural development, p. 3 (February 2001),

http://ec.europa.eu/agriculture/publi/reports/sustain/ index_en.pdf

Eurostat, European commission. population structure and ageing (2010), http://epp.eurostat.ec.europa.eu/statistics_explained/ index.php/Population_structure_and_ageing

Eurostat, research results. 2003. Cited in OSSATE Accessibility Market and Stakeholder Analysis (2005)

Galitz, W.O.: The essential guide to user interface design, pp. 579-584. John Wiley and sons, Inc., New York (2002)

García-Gallego, A., Georgantzís, N.: Good and Bad Increases in Ecological Awareness: Environmental Differentiation Revisited. Strategic Behavior and the Environment 1, 71-72 (2011)

Herzwurm, G., Mellis, W., Schockert, S., Weinberger, C.: Customer oriented evaluation of QFD Software tools, p. 5 (1997),

http://www.qfd-id.de/en/articles/evaluation_tools/ qfd-tools.pdf

IBM. Accessibility in Web 2.0 technology (2009), http: / /www. ibm.com/developerworks/web/library/ wa-aj-web20/index.html

Institute for energy, European commission. Code of conduct for data centres energy efficiency Version 1.0, pp. 3-7 (2008), http://ec.europa.eu/information_society/activities/ sustainable_growth/docs/datacenter_code-conduct.pdf

Kessler, E. B., Catts, R. Survey of Americans with Disabilities (2010), http://www.2010disabilitysurveys.org/indexold.html

Lányi, S.C., Forrai, S., Czank, N., Hajgató, A.: On developing validator software xvalid for testing home pages of universal design. In: Stephanidis, C. (ed.) Universal Access in Human-Computer Interaction, Coping with diversity, p. 285 (2007)

Lehtonen, M.: The environmental social interface of sustainable development: capabilities, social capital, institutions. Ecological Economics \#49, 199-214 (2004)

Lidwell, W., Holden, K., Butler, J.: Universal principles of design, revised and updated: 125 ways to enhance usability, influence perception, increase appeal, make better design decision, p. 16. Rockport publishers, Massachusetts (2010) 
Madruga, R.P.: The social dimension of sustainable development. United Nations expert meeting on National and International Cooperation for social development: Sharing of experiences and practices in social development, p. 2 (June 2002),

http: / / www. redem. buap.mx/pdf/ramon/pichs5.pdf

Marcu, M.: The EU-27 population continues to grow. In: Eurostat 2009, Population and social conditions (2009),

http://epp.eurostat.ec.europa.eu/cache/ITY_OFFPUB/

KS-QA-09-031/EN/KS-QA-09-031-EN.PDF

Nga, J.K.H., Soo, N.W.M.: The influence of personal attributes on perceptions of economic, social and environmental dimensions of sustainability. In: 2nd International Conference on Business and Economic Research, Paper \# 72, p. 2 (2010),

http: / /www. internationalconference.com.my/proceeding/ icber2010_proceeding/PAPER_072_PersonalAttributes.pdf

OneVoice for accessible ICT. Accessible ICT - Benefits to Business and Society (2010), http: / / www . onevoiceict.org/pdfs/Accessible\%20ICT\%20-

\%20Benefits\%20to\%20Business 20 and\%20 Society.pdf

Population Reference Bureau. 2010 World population Data Sheet (July 2010), http: / / www .prb.org/Publications / Datasheets / 2010/2010wpds . aspx

Pühretmair, F., Miesenberger, K.: Making sense of accessibility in IT Design - usable accessibility vs. accessible usability. In: Proceedings of the 16th international Workshop on Database and Expert Systems Applications (DEXA 2005), 1529-4188/05, p. 2. IEEE Computer society, Los Alamitos (2005)

Rüttimann, B.G.: Modelling Economic Globalization: A Post-Neoclassic View on Foreign Trade and Competition, pp. 17-20. Monsenstein and Vannerdat, Muenster (2007)

Standard \& Poors. Global Aging 2010: An Irreversible Truth (2010), http: / /www.standardandpoors. com/products-services/articles / en/us / ?assetID=1245229586712

Thatcher, J., Burks, M.R., Heilmann, C.: Web Accessibility -Web standards and regulatory compliance, p. 42 et seq. Springer, New York (2006)

The European Research Group's. Eurobarometer, 54.2/2001 (2001)

United Nations enable. Nations Convention on Rights of Persons with Disabilities (2007), http: / / www. un.org/disabilities/default.asp?id=150

Verma, N.: Business Process Management: Profiting from Process, pp. 1-4. Global India publications pvt ltd., New Delhi (2009)

Wegge, K.P., Zimmermann, D.: Accessibility, Usability, Safety, Ergonomics, Concepts, Models and Differences. In: Stephanidis, C. (ed.) HCII 2007, Part I. LNCS, vol. 4554, pp. 294 301. Springer, Heidelberg (2007)

World economic forum. ICT for economic growth: A dynamic ecosystem driving the global recovery, pp. 1-7 (2009),

https: / /members. weforum. org/pdf / ict/ICT\%20for\%20Growth.pdf

W3C. Web Content Accessibility Guidelines (WCAG) 2.0 (December 11, 2008),

http: / / www .w3 .org/TR/2008/REC-WCAG2 0-20081211/ 